\title{
Effect of Mastery Learning Approach on Senior School Students' Academic Performance and Retention in Circle Geometry
}

\author{
Saidat Morenike Adeniji \\ Department of Science Education, University of Ilorin, Ilorin, Nigeria, \\ saidatmorenike@yahoo.com \& salaudeen.sm@unilorin.edu.ng
}

\section{Saka Khadijat Ameen}

PhD., Department of Science Education, University of Ilorin, Ilorin, Nigeria, ameen.sk@unilorin.edu.ng

\section{B. U. Dambatta}

PhD., Sa'adatu Rimi college of Education, Kano State, Nigeria

\section{Razak Orilonise}

Department of Science Education, University of Ilorin, Ilorin, Nigeria

This study examined the effect of mastery learning on senior secondary school students' achievement and retention in circle geometry. The study was conducted in Ilorin, Kwara state, Nigeria. It adopted a quasi-experimental, non-randomized, pre-test, post-test control group design. A sample of 172 senior school II students was drawn from four co-educational schools using multi-stage sampling technique. Instrument for data collection was Circle Geometry Achievement Test (CGAT) which was validated by experts and reliability index of 0.82 was obtained using test-retest method. The result showed that senior school students' achievement in Geometry improved significantly when taught circle geometry using mastery learning approach. There was no gender difference found as well as no difference in the achievement of low, medium and high scoring students when taught with mastery learning approach. There was also a significance difference in the post test mean score and retention score of students taught circle geometry using mastery learning approach. It was recommended among others that trainings should be given to mathematics teachers on how to effectively use mastery learning approach in mathematics classroom if better performance is desired.

Keywords: mastery learning approach, academic performance, retention, students' score levels, circle geometry

Citation: Adeniji, S. M., Ameen, S. K., Dambatta, B. U., \& Orilonise, R. (2018). Effect of Mastery Learning Approach on Senior School Students' Academic Performance and Retention in Circle Geometry. International Journal of Instruction, 11(4), 951-962. https://doi.org/10.12973/iji.2018.11460a 


\section{INTRODUCTION}

Teaching is said to be a complex problem-solving activity which involves the transmission of right values, skills and knowledge between at least two individuals that is, the teacher and the learner. According to Abimbola (2009), teaching involves giving instruction to somebody on knowledge, skills and attitudes with the intention that the person will be able to act in a particular way that is compatible with the instruction. Teaching is associated with various responsibilities such as transmitting appropriate knowledge, developing individuals to cultivate good habits, creating awareness in order to appreciate national goals and developing individuals who can survive and compete globally. Responsibilities in teaching include planning, implementing and evaluating. For the process of teaching to be completed, learners need to be assessed. Teaching can then be seen as being central to education. The main purpose of teaching is to learn. Teaching is done in order to facilitate students' learning.

In educational context, teaching and learning go hand in hand because teaching cannot be imagined without a teacher, a learner and the subject matter. Learning is the process whereby an attempt is made to change the behavior of individuals through reinforced experiences brought about by external factors such as organized teaching. Learning is said to take place when there is a relatively permanent change in the behavior of an individual and the change is as a result of acquisition of new knowledge or skills. According to Daramola (1994), the three major stages in learning are the acquisition stage, retention stage and the retrieval stage. For the aim of teaching to be achieved, these three stages of learning need to be demonstrated by students. Students' learning is directly proportional to their performances.

Teaching and learning are done in respective subjects so that students could pass both internal and external examinations distinctively. However, in mathematics, students' performances have not been satisfactory as demonstrated by educational stakeholders. This was confirmed by the West African Examinations Council (WAEC) Chief Examiners' report of 2014 and 2015 where candidates who had credit and above are $61.97 \%$ and $65.94 \%$, respectively. Furthermore, it was expressed by the report that candidates do not perform well in some aspect of mathematics which may contribute to their low performance in the subject. Part of the aspect of mathematics that indicated candidates' weakness is circle geometry. WAEC 2014 and 2015 Chief Examiners' Report stated that circle theorems and angles on parallel lines among others were poorly attempted by majority of the candidates. It was then suggested by the report that mathematics teachers should lay more emphasis on the identified weak areas during mathematics instruction and lead the students to appreciate the application of mathematical concepts in everyday living.

Mathematics is essentially a subject where doing is more prominent that reading and it is one of the important subjects at secondary school level. Many reasons have been attributed to the unsatisfactory performance of students in mathematics and particularly in geometry among which is teachers' poor teaching methods (Olunloye, 2010). It was therefore recommended that teachers should improve on their teaching method if better understanding and application of geometry are desired which will in-turn lead to better 
performance. With regards to teachers' teaching and students' learning, Bloom (1976) believed that all students can eventually learn and retain equally complex or difficult material but some will learn faster than the other, hence, the background to mastery learning. According to (Wong \& Kang, 2012), mastery learning involves a set of clear steps for selecting content, teaching and determining students' progress. The basic assumptions of mastery learning are that all students can learn all important content to a level of excellence and the primary functions of schools are to define learning objectives and to help all students to achieve them putting in mind that students have varying capabilities in terms of cognitive development.

The main goal of mastery learning approach is to have all students learn instructional material at roughly equivalent and high levels. Instructors who use mastery learning break down course material into manageable units and create formative tests for students on each unit, until a relatively high performance is attained by all the students in the formative test of a particular unit before the students can progress into the next unit of content. And there will be remedial classes with parallel test for students who failed to meet up with the targeted criteria. After learning has taken place, the next stage is the retention stage. At the retention stage of learning, new information is processed by relating it to existing knowledge. Processes of the information may be facilitated usually through organized teaching which involves related assignments, illustrations and so on (Daramola, 1994). When new information has been meaningfully related to existing knowledge, such information is stored in the memory for future use and with this, retention is assured. Hence, this study examined the effect of mastery learning approach on students' achievement and retention in circle geometry.

\section{LITERATURE REVIEW}

Mastery learning has its roots in the Blooms theory of school learning which stated that all students can learn at high levels if appropriate conditions and time are given. He hypothesised that a classroom with mastery learning as opposed to the conventional mode of instruction would reduce the gaps of performance between learners of different degrees of academic abilities (Blooms, 1968). The major characteristics of mastery learning are breaking of content to sub-units, clear objectives, initial instruction, remediation lessons, formative and summative tests and immediate feedback.

Mastery learning considers learners individual differences such as pace of learning, level of mastery, time and so on. The time required for learning same material is different for each student. Mastery learning maintains that students must achieve a level of mastery in a pre-requisite knowledge before moving to the next learning material. If a student does not attain a level of mastery, such student would be introduced to remediation lessons where review of information and learning support would be given and then they would be tested again. The cycle continues until the learners can demonstrate or attain mastery level of $80 \%$ and above (Anderson, 2000). At this point, they can move to the next stage of learning. This will continue until all the learning objectives are achieved.

Mastery learning has been observed to improve students' performance as reported from studies. A meta-analysis study carried out by (Kulik et al., 2013) on 108 studies on the 
effectiveness of mastery learning revealed that mastery learning has positive effects on the academic performance of students at schools. However, the effect is more noticeable on the weaker students.

\section{Statement of the Problem}

Mathematics is one of the compulsory subjects at the basic, upper-basic and secondary schools in Nigeria (FRN, 2013). However, students' performance in the subject has not been satisfactory. One of the identified causes of unsatisfactory performance is teachers' use of inappropriate instructional strategies (Salman et al., 2012). Aside this, several factors can influence the performance of students in mathematics some of which are gender, attitude, scoring levels and learning styles. Researches have been carried out on the effect of mastery learning approach on students' academic performance in mathematics and science. Abakpa and Iji (2013); Akinsola (2007); Kazu, et al. (2008); Udo \& Udofia (2014); and Zakariyya et al. (2016) in different studies reported that mastery learning approach improved students' performances. Although, none of these studies examined the effect of mastery learning approach on students' retention ability. Also, these studies were not carried out in Ilorin and circle geometry was not the content scope. The present study, therefore, compares the performances of students taught circle geometry with mastery learning approach and those taught conventionally. Also, the influence of gender and scoring levels on students' performance were examined because there was no conclusive result in literature. While it has been acknowledged that mastery learning approach could enhance students' performance in some subjects and topics as observed in literature, the study deem it fit to investigate whether the position could be extended to circle geometry.

\section{Purpose of the Study}

The main purpose of this study was to determine the effect of mastery learning approach on students' performance in circle geometry in Ilorin, Nigeria. Specifically, this study investigated:

1. The effect of mastery learning approach on students' performance in circle geometry

2. Whether a significant difference exists in the performance of male and female students taught circle geometry using mastery learning approach

3. Whether a significant difference exists in the performance of high, medium and low scoring students taught circle geometry using mastery learning approach

4. Whether a significant difference exists in the posttest scores of students taught circle geometry using mastery learning approach and their retention scores.

\section{METHOD}

The study was a quasi-experimental research involving pretest, posttest, non-randomized and non-equivalent control group design. It adopted a 2 × 2 × 3 research design. The first two (2) represents treatment at two levels (students taught using mastery learning approach and those taught conventionally). The next two (2) is students' gender 
occurring at two levels (male and female) while the last three (3) represents students' scoring level occurring at three levels (high, medium, low). The study also involved a retention test. The schematic representation of the design is illustrated below

$\begin{array}{cccc}\text { Pretest } & \text { Treatment } & \text { Posttest } & \text { Retention } \\ \mathrm{O}_{1} & \mathrm{X} & \mathrm{O}_{2} & \mathrm{O}_{3} \\ -\mathrm{O}_{1} & & \mathrm{O}_{2} & \mathrm{O}_{3}\end{array}$

Where:

$\mathrm{O}_{1}$ is the pretest for the experimental and control groups

$\mathrm{O}_{2}$ is the posttest for the experimental and control groups

$\mathrm{O}_{3}$ is the retention test for the experimental and control groups

$\mathrm{X}$ is the mastery learning approach used to teach the experimental group indicates non-randomization of the groups

The population for this study was all senior school students in Ilorin while the target population was all senior school two students. Multi-stage sampling technique was used to select the participating students. Four equivalent schools were purposively selected based on schools that are co-educational and those that have presented students for external examinations for over ten years. In each of the selected schools, one intact SS II class with fair representation of male and female students take part in the study. The experimental group consisted of 40 male and 38 female students while the control group consisted of 44 male and 50 female students. The students in each of the selected classes were categorised into high, medium and low scoring levels based on their cumulative scores in mathematics in the previous term. Students who score $70 \%$ and above were categorised as high scorers; those who score between $41 \%$ and $69 \%$ were classified as medium scorers while those whose score is $40 \%$ and below were low scorers. Based on the ethnographic nature of the study and preference for intact classes, it is believed that there is a fair representation of the samples. Generally, four intact classes formed the experimental and control groups for the study in which two classes were taught circle geometry using mastery learning approach while the other two classes were taught circle geometry conventionally. The researcher ensured that the pre-requisite to the content of circle geometry had been taught before the study.

The research instrument for this study was the Circle Geometry Achievement Test (CGAT), which serves as pretest, posttest and retention test. It comprises of two sections namely, section A and B. Section A was on students'_bio data while section B consists of 40 multiple choice and 5 theory questions using the West African Senior School Certificate Examinations (WASSCE) past questions as guide. The items of CGAT centered on circle geometry. The items on CGAT were validated by two mathematics educators and two senior school mathematics teachers. All necessary corrections and 
suggestions were made. The CGAT was administered to thirty five (35) students drawn from non-participating secondary schools. Test re-test method was used to determine the reliability of the instrument. A reliability coefficient of 0.82 was obtained using Pearson Product Moment Correlation (PPMC) at 0.05 level of significance.

The study lasted for two weeks, pretest was given to both experimental and control groups in order to make sure that the two groups are equivalent, after which the experimental group was exposed to the treatment, the treatment goes thus: the content scope which was circle geometry was sub-sectioned into four parts. In the first class after the pretest, students were taught the first part of the circle geometry and a formative test $\left(1^{\mathrm{a}}\right)$ with scope from what was taught was given to them. Students' scripts were marked and if up to two-third of the members of a class missed a question, correction to the question was treated generally but if otherwise, students were grouped such that those that answered the question correctly were placed in each group so that they can correct their peers of their mistakes. After the correction, students were given formative test $\left(1^{\mathrm{b}}\right)$, students' scripts were marked and corrections were made on the basis of the percentages that missed a particular question. This continues until the content for the first class is being mastered. When more than two-third of the class members scored $80 \%$ and above, this indicated that they have mastered the content and hence, they can now move to the second part of the content.

For the second class, the teacher taught the aspect of circle geometry that falls to this category and formative test $\left(2^{\mathrm{a}}\right)$ was given to the students and the students script were marked and corrections were made in accordance with the percentage that missed a particular question. After which formative test $\left(2^{\mathrm{b}}\right)$ was also given until mastery level is attained. This continued for formative test $3^{\mathrm{a}}, 3^{\mathrm{b}}, 4^{\mathrm{a}}$ and $4^{\mathrm{b}}$. The content of formative test $1^{\mathrm{a}}$ and $1^{\mathrm{b}}$ are the same, likewise $2^{\mathrm{a}}$ and $2^{\mathrm{b}}, 3^{\mathrm{a}}$ and $3^{\mathrm{b}}, 4^{\mathrm{a}}$ and $4^{\mathrm{b}}$ are the same. The percentage of students that have mastered a particular content at each stage of the formative test determines the number of formative test that would be administered to them before proceeding to the next content.

The control group was taught circle geometry using conventional method. In this class, the researcher assumes a normal teaching environment to achieve the stated objectives. The conventional method of teaching involves the chalk, chalkboard and talk method. Students are actively involved in the teaching and learning process but they were not exposed to any special treatment. At the end of the teaching, students were given assignment from their textbook. The assignment was marked and recorded. After two weeks of the post test, a retention test was administered to the experimental group.

The data obtained from the pre, post and retention tests were used for analysis. Descriptive statistics (Mean and Standard deviation) was used to answer the research questions. Independent $t$-test was used to test whether significant difference existed in the means of the experimental and control groups. Also, in order to test whether the means of the different scoring levels were equal across the independent variable (treatment), Analysis of Covariance (ANCOVA) was used since there was no randomization of the group, three levels of scorers (high, medium and low) were 
involved, and the pre test scores was used as covariate. Here, it is assumed that the relationship between the dependent and independent variable is linear.

\section{FINDINGS}

Research Question I: Is there a difference in the performance of students taught circle geometry using mastery learning approach and those taught conventionally?

Hypothesis I: There is no significant difference in the performance of students taught circle geometry with mastery learning approach and those taught conventionally

The result from table 1 indicated that the mean score of students taught circle geometry using mastery learning approach was 77.31 while those taught circle geometry using conventional method was 32.94 . This means that students taught circle geometry using mastery learning gained higher than those taught using conventional method. Also, from table $1, t_{(170)}=24.24, \mathrm{p}<0.05$, since the $\mathrm{p}$-value is less than the level of significance (0.05), the null hypothesis was rejected and therefore, there seems to be significant difference in the performance of students taught circle geometry using mastery learning approach and those taught conventionally.

Table 1

t-test analysis of posttest scores of students taught with mastery learning approach and those taught conventionally

\begin{tabular}{lllllll}
\hline Group & $\mathrm{N}$ & Mean & SD & df & $t$-value & $p$-value \\
\hline Experimental & 78 & 77.31 & 8.80 & & & \\
Control & 94 & 32.94 & 14.04 & & & \\
\hline
\end{tabular}

$\mathrm{p}<0.05$

Research Question II: Is there a difference in the performance of male and female students taught circle geometry using mastery learning approach?

Hypothesis II: There is no significant difference in the performance of male and female students taught circle geometry using mastery learning approach

Table 2 shows the mean score of male and female students taught circle geometry with mastery learning approach. Male students had a mean score of 77.40 while their female counterpart had a mean score of 77. 21. This indicated that male students benefitted higher than the female students. In order to test for the significance in the difference, $t$ test analysis was carried out with $t_{(76)}=0.09, p>0.05$, since the $\mathrm{p}$-value is greater than the level of significance (0.05), the null hypothesis was not rejected and therefore, there seems not to be significant difference in the performance of male and female students taught circle geometry using mastery learning approach.. 
Table 2

$\boldsymbol{t}$-test analysis of posttest scores of male and female students taught with mastery learning approach

\begin{tabular}{lllllll}
\hline Group & $\mathrm{N}$ & Mean & SD & df & $t$-value & $p$-value \\
\hline Male & 40 & 77.40 & 9.96 & & & \\
Female & 38 & 77.21 & 7.51 & & & \\
\hline$p>0.05$ & & & & & \\
\hline
\end{tabular}

$\mathrm{p}>0.05$

Research Question III: Is there a difference in the performance of high, medium and low scoring students taught circle geometry using mastery learning approach?

Hypothesis III: There is no significant difference in the performance of high, medium and low scoring students when taught circle geometry using mastery learning approach

Table 3 indicated that there was no significant difference in the performance of low, medium and high ability level students taught circle geometry using mastery learning approach, $F_{(2,74)}=1.00, p>0.05$. Since the $p$-value was greater than 0.05 level of significance. Hence, hypothesis three which states that there was no significant difference in the performance of low, medium and high scoring students taught circle geometry using mastery learning approach was not rejected.

Table 3

ANCOVA computation based on scoring levels of students taught circle geometry using mastery learning approach

\begin{tabular}{llllll}
\hline Source & Type III Sum of Squares & df & Mean Square & $F$ & Sig. \\
\hline Corrected Model & 157.03 & 3 & 52.35 & 0.67 & 0.58 \\
Intercept & 26878.25 & 1 & 26878.25 & 342.36 & 0.00 \\
Pretest & 1.86 & 1 & 1.86 & 0.02 & 0.88 \\
Ability level & 156.40 & 2 & 78.20 & 1.00 & 0.37 \\
Error & 5809.58 & 74 & 78.51 & & \\
Total & 472132.00 & 78 & & & \\
Corrected Total & 5966.62 & 77 & & & \\
\hline a. R Squared = 26 (Adjusted R Squared =-0.13)
\end{tabular}

Research Question IV: Is there a difference in the posttest scores and retention scores of students taught using mastery learning approach?

Hypothesis IV: There is no significant difference in the posttest scores and retention scores of students taught using mastery learning approach

Table 4 shows the paired t-test analysis of students' scores for posttest and retention. The mean for the posttest was 77.31 while that of the retention was 63.75 . This means that students' post test score was higher than the retention score. In order to test whether significant difference exist in the posttest and retention scores, paired t-test analysis was carried out with $t_{(71)}=5.39, p<0.05$. Since $\mathrm{p}$ is less than the significant level $(0.05)$, hypothesis IV was rejected and there seems to be a significant difference in the performance of students in the posttest and retention. 
Table 4

$t$-test analysis of posttest and retention scores of students taught with mastery learning approach

\begin{tabular}{lllllll}
\hline Group & N & Mean & SD & df & t-value & p-value \\
\hline Posttest & 72 & 77.31 & 9.04 & & & \\
Retention & 72 & 63.75 & 21.89 & & & \\
\hline$p<0.05$ & & & & & &
\end{tabular}

\section{Summary of Major Findings}

1) There was a significant difference in the performance of students taught circle geometry using mastery learning approach and those taught conventionally in favour of mastery learning

2) There was no significant difference in the performance of male and female students taught circle geometry using mastery learning approach

3) There was no significant difference in the performance of high, medium and low ability students taught circle geometry using mastery learning approach

4) There was a significant difference in the posttest scores of students taught circle geometry using mastery learning approach and their retention score

\section{DISCUSSION}

The study investigated the effects of mastery learning approach on students' performance and retention in circle geometry. The result of the finding showed that the post-test mean score of students in the experimental group (77.31) was higher than the mean score of control group (32.94). Also, there was a significant difference in the performance of students in the experimental and control group. This means that students in the experimental group who were taught circle geometry using mastery learning approach performed significantly better than the control group. The higher performance of students in the experimental group may be as a result of the opportunity that students could pace their own learning and the remediating lesson which students were continuously exposed to. Although, students in the experimental group required slightly more time for their instruction when compared to the control group.

The result of this study is similar to that of Zakariyya et al. (2016) and Abakpa \& Iji (2013) where the researchers found significant difference in the performance of students when taught geometry using mastery learning approach. Also, the result which indicated that male and female students achieved equally when taught geometry using mastery learning approach was in agreement with Zakariyya et al., (2016) and Abakpa \& Iji (2013). It is however in disagreement with the findings of Udo \& Udofia (2014). The implication of this finding is that mastery learning is appropriate for bridging the gap of male and female performance in circle geometry.

There was no significant difference in the performance of high, medium and low scoring students. This implies that high, medium and low scoring students achieved equally from using mastery learning approach. It was therefore observed that this approach has 
the potential of levelling the performance of high, medium and low scoring students. This finding is in line with (Abakpa \& Iji, 2013) who found no significant difference in the geometry achievement scores of high and low ability students when taught using mastery learning approach.

Furthermore, there was a significant difference in the post-test mean score of students taught with mastery learning approach as compared to the retention mean score in favour of the post-test. This implies that while the formative tests were being carried out, students retain higher contents than when the retention test was carried out. Conclusively, the results of the study are consistent with the predictions of mastery theory which are higher academic scores; reduced variation in test scores; reduction in some individual differences (such as age, gender) that exists among learners.

\section{CONCLUSION}

It can be concluded from the findings of the study that mastery learning approach improves students' performance. Both male and female students benefitted equally when taught using mastery learning approach. Also, mastery learning approach is effective in influencing students' different scoring levels to achieve equally in given task. Hence the educational inequality especially in terms of gender and score level may be reduced when mastery learning approach is used. In addition, this approach may not be reliable for facilitating students' retention of subject matter. The limitation of mastery learning is that it requires slightly more instructional time before students could demonstrate mastery of the first learning material.

\section{RECOMMENDATIONS}

Based on the findings of this study, the following recommendations were made:

1.) Mastery learning approach should be used by mathematics teachers especially for teaching difficult concept in mathematics.

2.) Since mastery learning approach is not gender bias, male and female students should be given equal priority in mathematics classes especially when mastery learning approach is being used.

3.) Mastery learning approach should be adopted for teaching when bridging the gap of low, medium and high scoring students is desired.

4.) Workshop and seminars should be organized by the government and professional associations for mathematics teachers on how to effectively incorporate mastery learning in the teaching of mathematics. 


\section{REFERENCES}

Abakpa, B. O. \& Iji, C. O., (2013). Effect of Mastery learning approach on senior secondary school students in geometry. Journal of Science Teachers Association of Nigeria (STAN). 12(1), 1-11.

Abimbola, I.O. (2009). A brief history of teaching, In fundamental principles and practice of Instruction. Edited by I.O. Abimbola \& A.O. Abolade. Published by the Department of Science education \& art and social science education. 1-23.

Akinsola, M. K. (2007). Mastery learning, co-operative mastery learning strategies and students' achievement in integrated science. Department of Teacher Education,

University of Ibadan, Nigeria. Retrieved from http://www.ipn.unikiel.de/projket/esera/book/1132

Anderson, J. R. (2000). Learning and memory: An integrated approach ( $2^{\text {nd }}$ edition). New York: John Wiley and Sons, Inc.

Bloom, B. (1976). Human Characteristics and school learning. New York; McGrawHill.

Bloom, B. (1968). Learning for Mastery. Evaluation comment, 1(2), 1-5. Los Angeles Centre for study of evaluation Instructional Programmes (UCCLA).

Daramola, S. O. (1994). Basic concepts in educational processes. Basic Principles of Instruction. Lekan printing press, New Yidi road, Ilorin. 1-9.

Federal Republic of Nigeria, (2013). National Policy on Education (Revised). Lagos: NERDC Press.

Kazu, Y. I., Kazu, H. \& Ozedemir E. (2005). The effect of mastery learning model on the success of the students who attended usage of information technologies course.

Educational Technology and Society. 8(4), 233-243.

Kulik, C. C., Kulik, J. A. \& Bangert-Drowns R. L. (2013). A meta-analysis on the effectiveness of mastery learning programs. American Educational research Association, 60 (2), 265-299.

Olunloye, O. (2010). Mass Failure in Mathematics: a National Disaster. Tribune of 07/02/2010 Retrieved from http:www/tribune.com.nig.

Salman, M. F., Mohammed, A. S., Ogunlade, A. A., \& Ayinla, J. O. (2012). Causes of mass failure in senior school certificate mathematics examinations as viewed by secondary school Teachers and Students in Ondo, Nigeria. Journal of education and Practice, 3(8), 79-87.

Udo, M. E. \& Udofia T. M. (2014). Effects of mastery learning strategy on students' achievement in symbols, formulae and equations in chemistry. Journal of educational research and reviews, 2(3), 28-35. 
West African Examinations Council (WAEC) (2014). May/ June Chief Examiner's Report on Mathematics.

West African Examinations Council (WAEC) (2015). May/ June Chief Examiner's Report on Mathematics.

Wong B. S. \& Kang L. (2012). Mastery learning in the context of university education. Journal of the NUS Teaching Academy, 2(4), 206-222.

Zakariyya A. A., Ndagara A. S. \& Yahaya A. A. (2016). Effects of mastery learning approach on senior secondary school students' performance in geometry in bida, Niger state, Nigeria. ABACUS: Journal of the Mathematical Association of Nigeria (MAN). 41(1), 17-25. 